\title{
Clinical outcomes of contemporary
} lateral augmentation techniques in primary $A C L$ reconstruction: a systematic review and meta-analysis

\author{
Lucas Beckers $^{1+} \mathbb{D}$, Thiago Vivacqua ${ }^{1 \dagger}$, Andrew D. Firth $^{2}$ and Alan M. J. Getgood ${ }^{1 *}$
}

\begin{abstract}
Purpose: The purpose of this investigation was to systematically review the contemporary literature to determine if a lateral augmentation (LA) added to an Anterior Cruciate Ligament Reconstruction (ACLR) provides better clinical and patient reported outcomes compared to an isolated ACLR.

Methods: A systematic review and meta-analysis was performed according to the Preferred Reporting Items for Systematic reviews and Meta-analyses (PRISMA) criteria. Two authors independently conducted an electronic search using MEDLINE ${ }^{\circledR}$ and Embase ${ }^{\circledR}$ on February $6^{\text {th }}, 2021$ for level I-III randomized controlled trials (RCT) and prospective cohort studies without randomization, published after 2012 and with a minimum of two year follow-up. Publications were included when they reported on the objective knee stability examination, patient reported outcome scores, return to sports or graft rupture rate of any type of primary, isolated ACLR compared to ACLR combined with any type of LA.

Results: A total of 11 studies that reported on a combined total of 1892 unique patients were eligible for data extraction, including five RCTs and six prospective cohort studies. In 6 studies, an Anterolateral Ligament reconstruction (ALLR) was the LA of choice, while the 5 other publications used different types of Lateral Extra-articular Tenodesis (LET). A significant reduction in graft ruptures was found in patients treated with $A C L R+L A(3 \%)$ compared to isolated ACLR (12\%). Rotational laxity was significantly higher in isolated ACLR (14\%) compared to ACLR + LA (6\%). Addition of a $L A$ reduced anterior translation when assessed via instrumented laxity testing. No significant difference was found in the patient reported outcome scores (IKDC and Tegner) between both patient groups, except for the Lysholm Score which was significant in favour of the ACLR + LA group.
\end{abstract}

Conclusion: Combination of a primary ACLR with a LA can significantly reduce the risk of graft rupture and provide better rotatory stability, without jeopardizing patient reported outcomes.

Level of evidence: Level III, Systematic Review of Level I, II and III studies.

Keywords: ACL, Anterior cruciate ligament reconstruction, Systematic review, Meta-analysis, Lateral extra-articular tenodesis, Anterolateral ligament, Pivot Shift, Rotational instability

\footnotetext{
*Correspondence: agetgood@uwo.ca

† Lucas Beckers and Thiago Vivacqua contributed equally to this work.

${ }^{1}$ Department of Orthopedic Surgery, Fowler Kennedy Sport Medicine Clinic, University of Western Ontario, 3M Centre, 1151 Richmond Street, London, ON N6A 3K7, Canada

Full list of author information is available at the end of the article
}

\section{Introduction}

One of the major 'hot topics' in Orthopaedic Sports Medicine in the past decade has been the identification and anatomical description of the anterolateral ligament (ALL) [5, 59]. An important reason for the 
extensive attention to the 'rediscovery' of this structure was its assumed role in the rotatory stabilization of the anterior cruciate ligament (ACL) injured knee $[2,5,42,61]$. Along with the ALL's recognition, more emphasis was subsequently placed upon the anterolateral complex (ALC) [12]. This interrelated group of structures on the lateral side of the knee, including the superficial and deep iliotibial band (ITB) with its related capsulo-osseous layer, and the ALL [5, 40, 59] has been proven to assist in the control of the rotatory laxity of the knee [11, 12, 23, 29]. Subsequently, augmentations of the ALC have been considered by some as a breakthrough in the attempt to enhance the survival and outcome of ACL reconstruction (ACLR) [30, 31]. This increased interest has resulted in a plethora of publications on several aspects of the ALC, mainly addressing the ALL. However, contradictory data on the role and the necessity for an ALC repair/augmentation in the setting of primary ACL injured knees resulted in a divergent standpoint regarding this additional procedure in the Orthopaedic sports community $[16,34,43,46]$. This has been amplified by limited high-quality clinical research addressing the relevance and clinical outcomes of lateral augmentations (LA) as a whole [33, 49].

As a response to this controversy, a consensus was formulated on the anatomical description of the different elements of the ALC, along with the recognition of its role in the control of anterolateral subluxation of the knee [12]. The summary of recent biomechanical investigations observed that, except for minor differences between different types of reconstructions, the most common types of LA (e.g. ALL reconstruction, ITB based Lateral extraarticular Tenodesis (LET), Over-the-top ACLR with lateral augmentation) have the potential, in combination with intra-articular ACLR, to restore the kinematics of an ACL injured knee to those closer to that of a native knee joint [6, $11,32,51]$.

Even in the face of this biomechanical data, and despite good outcomes of the additional LA procedures being published in small case-control series with longterm follow-up [10, 17, 44, 64], the evidence to add a LA procedure to primary ACLR in order to improve patient outcomes has remained controversial. Given the more recent publications of high-quality clinical trials suggesting a reduction in anterolateral rotatory laxity and re-rupture rates of primary ACLR when combined with a LA $[14,55]$, we sought to determine whether the addition of a LA to a primary ACLR also ensures better objective knee stability scores and patient reported outcomes compared to an isolated ACLR. We hypothesized that an ACLR combined with any type of LA would result in superior objective knee stability examination and patient reported outcomes.

\section{Methods \\ Search strategy}

A literature search was performed based upon the guidelines of the Preferred Reporting Items for Systematic reviews and Meta-analyses (PRISMA) statement [35]. An electronic search including MEDLINE ${ }^{\circledR}$ and Embase ${ }^{\circledR}$ databases was conducted on February $6^{\text {th }}, 2021$ by two authors (LB and TV). The search query was compiled based upon a combination of following key words and MeSh terms ((anterior cruciate ligament OR $A C L)$ AND reconstruction AND ((anterolateral AND (ligament OR complex)) OR (lateral extra-articular tenodesis OR LET) OR iliotibial band tenodesis) AND (clinical OR functional OR failure OR outcome)). The reference lists of included articles were carefully screened to identify additional eligible studies that were not retrieved by our electronic database search. All studies published from 2012 onwards were considered for inclusion in this systematic review if they met the eligibility criteria, as this was the year of publication of the early descriptions of the ALL.

\section{Eligibility criteria Type of subjects}

We included studies concerning patients with unilateral, isolated primary ACL injuries, indicated for a soft tissue ACLR with or without additional LA. Associated meniscal and osteochondral lesions in the ipsilateral knee, identified at the time of surgery with concomitant treatment, were no basis for exclusion. Studies were excluded based upon the use of synthetic grafts, both for the ACLR or the LA procedure, additional soft tissue procedures (ACL repair, multi-ligamentary reconstructions and meniscal transplant) or realignment procedures. Study specific inclusion and exclusion criteria of every eligible publication were listed, as well as extended indications for LA and separate failure criteria if reported (Table 1).

\section{Type of interventions and comparisons}

We aimed to compare isolated ACLR to ACLR combined with a LA procedure. All techniques of ACLR and LA procedure used were included, regardless the type of reconstruction (e.g. Single- or Double bundle), graft choice (e.g. Hamstrings, Quadriceps, Patellar tendon), graft fixation as well as the type and graft choice for LA (e.g. LET, ALL,...).

\section{Type of outcome measurements}

Objective stability scores and patient reported outcome scores were recorded (Table 2). Objective knee stability 


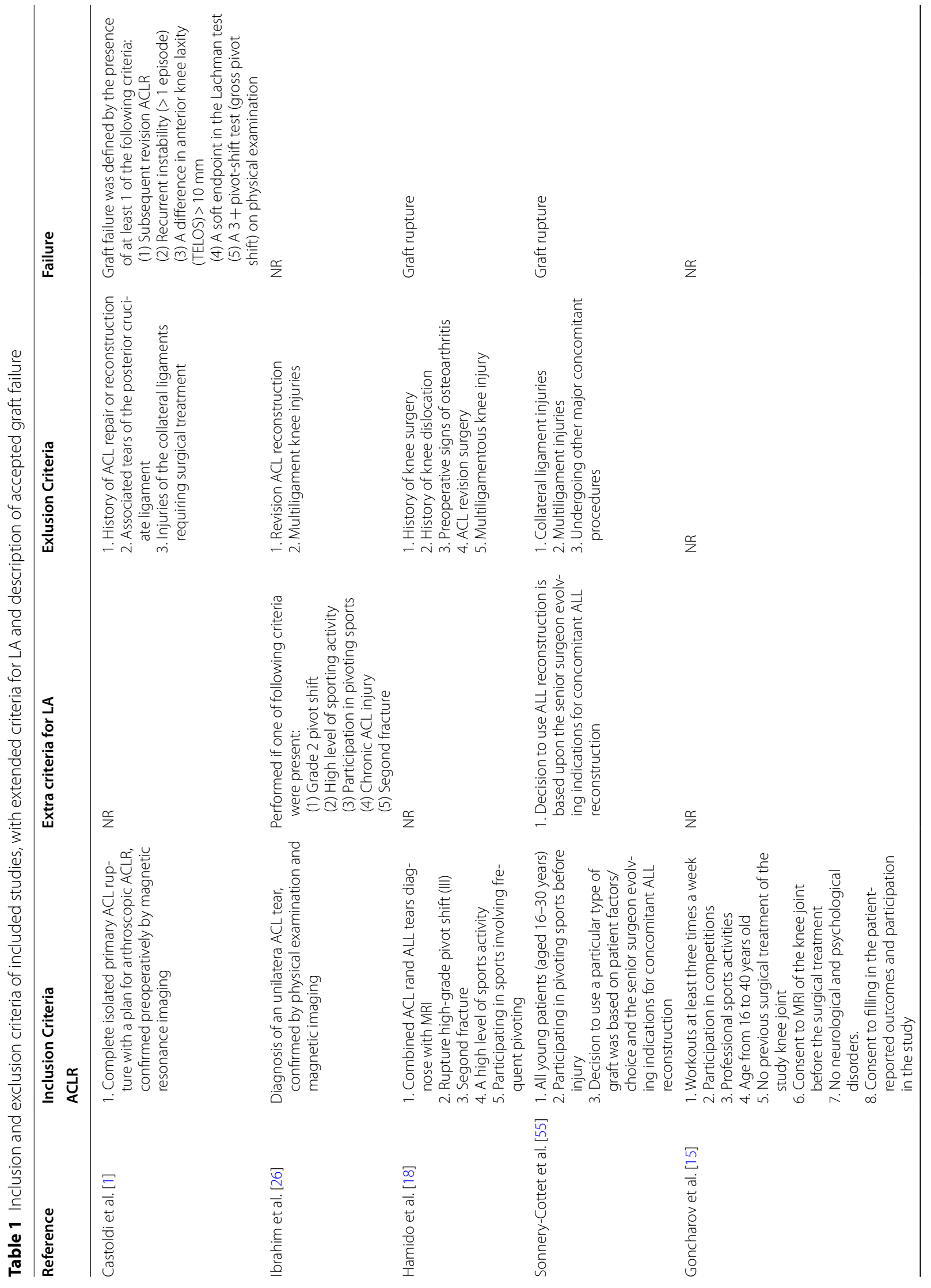




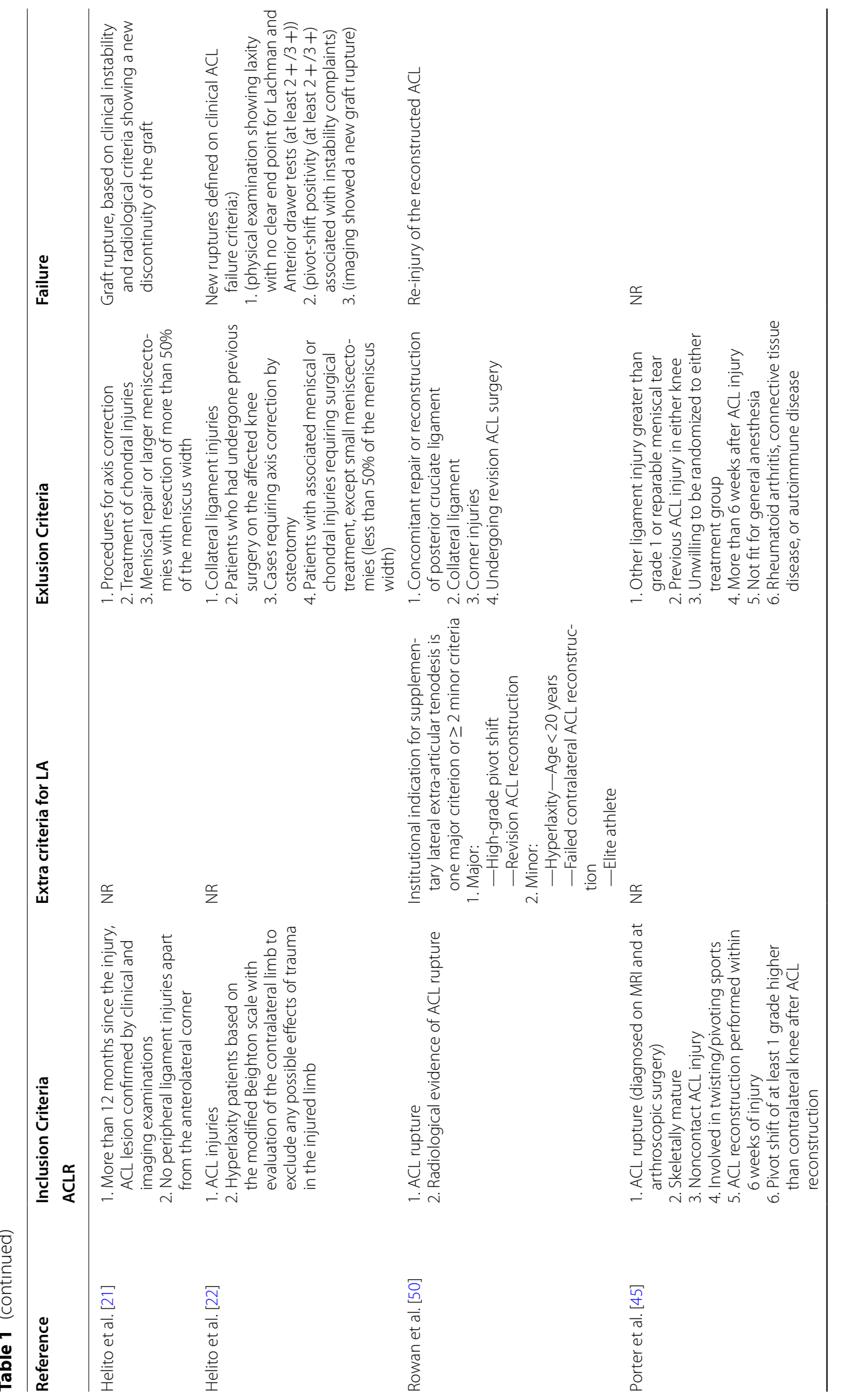




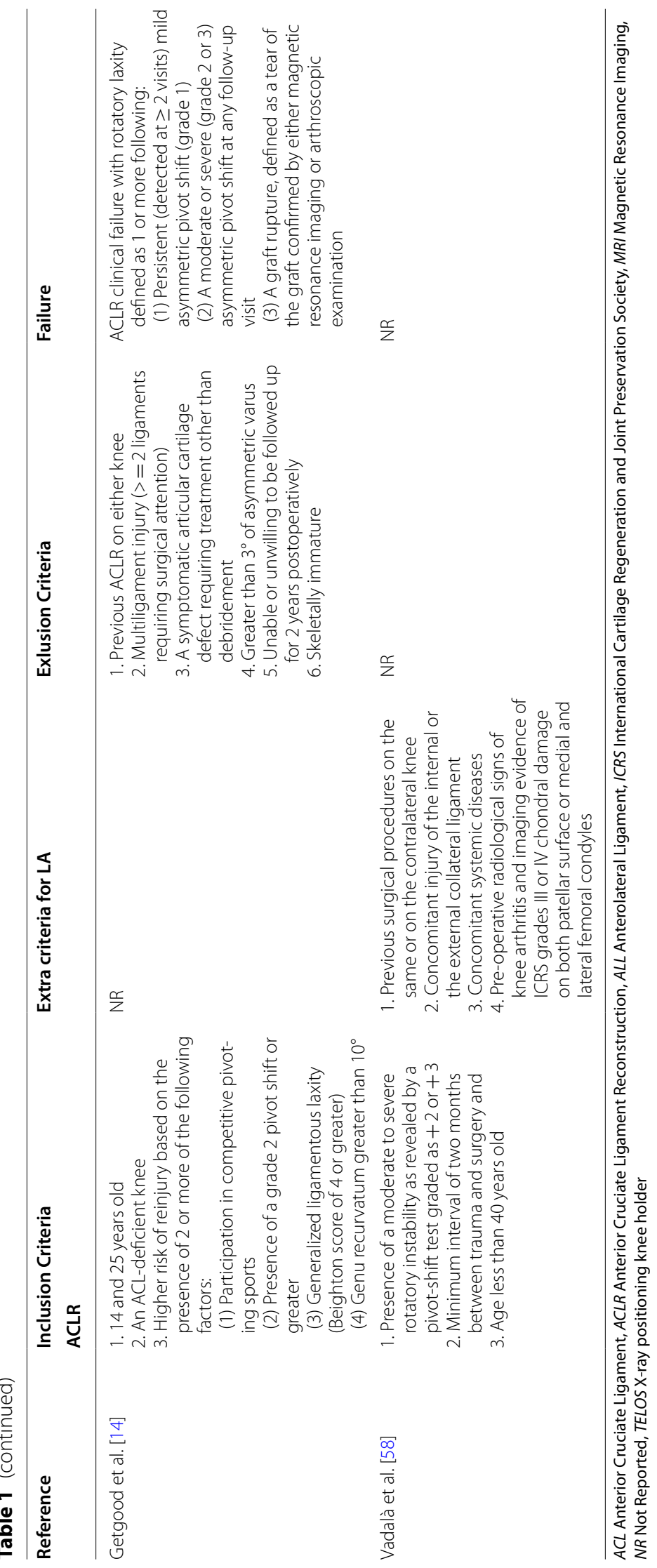




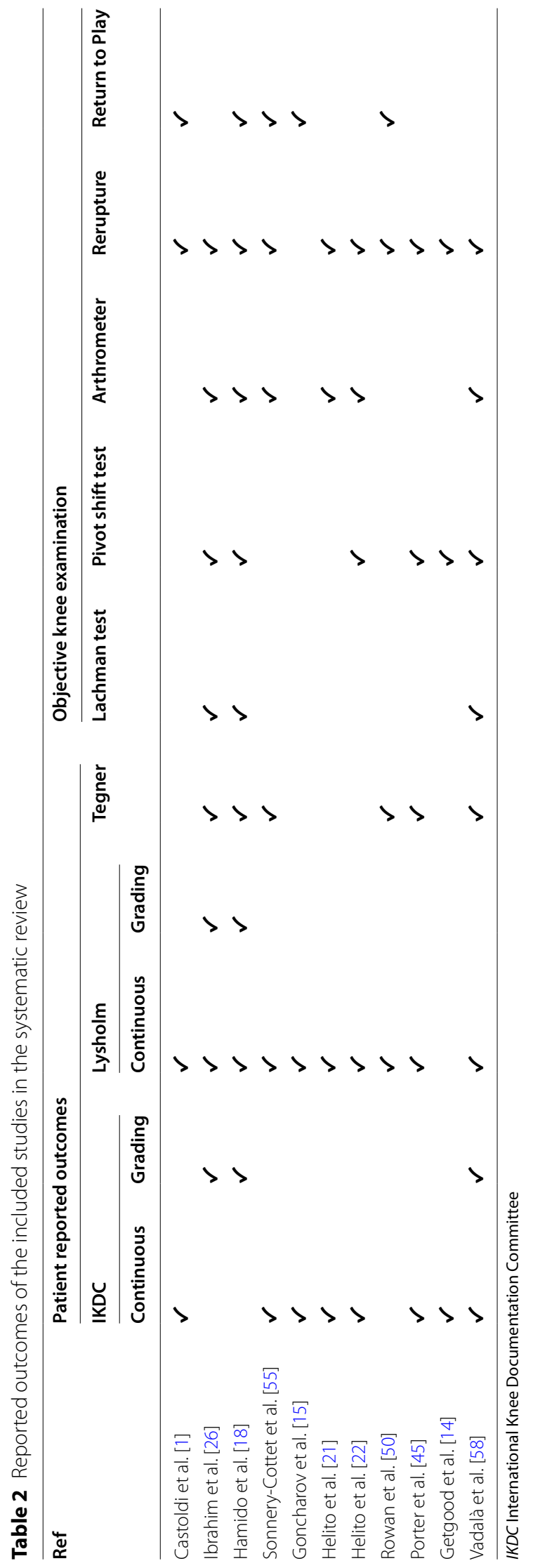


examination measurements included the Lachman and Pivot Shift tests. Instrumented laxity measurement with KT-1000 arthrometer was recorded where possible. Clinical failures were considered with a Lachman grade II or III and a Pivot Shift test grade II or III [14]. Patient reported outcomes comprised the International Knee Documentation Committee (IKDC) [19], Tegner Activity score [57] and Lysholm score [36]. Additionally, we obtained information on graft rupture rate and return to sports.

\section{Type of studies}

We included all Level I-III studies reporting on the clinical outcomes of primary, isolated ACLR compared to ACLR combined with LA with at least 2 years of followup, comprising randomized controlled trials (RCTs) and prospective cohort studies without randomization. We excluded retrospective cohort studies and case series without a control group as well as systematic reviews, biomechanical and in-vitro studies, expert opinions, conference proceedings/abstracts and editorial comments, as well as publications written in any language other than English.

\section{Study selection}

Two authors (LB and TV) independently screened the titles and abstracts of the identified studies obtained by the literature search and after removal of duplicate titles for their relevance (Fig. 1). All studies were considered for inclusion if they met the above stated inclusion criteria. A second, full text review was performed for the articles that passed the initial screening or in case of ambiguity in the title and abstract during the initial screening, unable to assess the eligibility of this publication on the limited information. In case of disagreement between the authors, the full text was reviewed conjointly and a decision was taken in consensus. A separate check of the reference lists of the included articles was performed to reveal publications that were initially missed during the literature search.

\section{Data extraction and quality assessment}

Two authors (LB and TV) independently extracted study demographic data (Study design, Level of evidence, inclusion period, inclusion- and exclusion criteria, surgical techniques for ACLR and LA procedures, objective outcome data and patient reported outcomes graft rupture rate and return to sports). Risk-of-bias assessment was performed to evaluate the methodological quality of eligible studies by using the Cochrane Collaboration Tool for randomized controlled trials [24] and the NewcastleOttawa Scale (NOS) for the included prospective cohort studies [65].

\section{Statistical analysis}

Statistical analyses and forest plots were performed using Cochrane Review Manager (version 5.3). Categorical outcomes were treated as dichotomous and the proportion of patients who had the event was determined. A pooled estimate of the overall odds ratio and 95\% confidence interval (CI) was calculated using a Mantel-Haenszel test and random-effects model. For continuous outcomes, a pooled mean difference and $95 \%$ confidence interval were estimated using inverse weighting and a randomeffects model. Standard deviation was estimated for studies that did not report a measure of variance according to the method described by Wan et al. [60]. We performed a sensitivity analysis to confirm that estimating variance did not significantly change the pooled treatment effect. The $\mathrm{I}^{2}$ statistic was used to assess between-study heterogeneity and was interpreted as low (25\%), moderate (50\%) or high $(75 \%)$ according to Higgins and Thompson criterion [25]. We made a priori hypotheses that heterogeneity may be explained by ALL graft choices (gracilis/ semitendinosus vs. IT band), study duration $(<3$ years vs. $>3$ years) or study design (RCT vs. cohort study). Statistical significance was set at $p<0.05$.

\section{Results}

\section{Systematic search and study selection}

The initial literature search identified 752 studies (353 in Medline and 399 in Embase). After removal of duplicates, 496 studies remained and were subject to the first screening. Following review of title and abstract, 467 were excluded leaving 29 studies for full text review. Of those, 17 studies did not meet the inclusion criteria leaving 12 studies eligible for inclusion in this systematic review. During the data extraction, we found overlapping inclusion periods for six separate studies published by three different groups, reporting on similar outcome data with ambiguity as to whether all the included patients were unique [13, 14, 21, 22, 54, 55]. The subgroup analysis regarding concomitant medial meniscal repair in ACL reconstructions by SonneryCottet et al. [54] shared a 17 month inclusion period (January 1, 2013 until May 31, 2014) with the previously published prospective cohort study [55]. This lead to an inevitable double patient inclusion as all patients with meniscal repair through a posteromedial portal were included. Therefore, this specific subgroup analysis was not included in this systematic review. Due to the lack of clarity regarding the patient groups published by Helito et al. [21, 22], the principal investigator was contacted and subsequently confirmed unique patient enrolment in both studies. Two studies published from the STABILITY 1 trail by Getgood et al. [13, 14] were also retrieved during the literature review. Both reported on graft 
re-rupture rate, but only patients and outcome data from the full RCT were retained for this systematic review [14]. Review of the included articles revealed one more article by Vadalà et al. eligible for inclusion [58]. Finally, 11 publications were assessed for systematic review and meta-analysis (Fig. 1).

\section{Characteristics of included studies}

Following a thorough systematic review and data extraction 1892 unique patients were included in 11 studies. Of these patients, 1057 were treated with isolated ACLR and another 835 underwent ACLR with an additional LA (Table 3). Bone-Patellar Tendon-Bone (BPTB) grafts were used in two studies in both groups [1, 15], where as one study used the BPTB graft only in the isolated ACLR cohort [55]. All the other studies used Hamstrings Tendons (HT) as the ACL graft in both groups. In total, isolated ACLR were based on 177 (17\%) BPTB and 880 (83\%) HT grafts, while ACLR + LA relied on 56 (7\%) BPTB and 779 (93\%) HT grafts. Anterolateral Ligament
Reconstruction (ALLR) was used as the LA in six studies (405 patients, 49\%) [15, 18, 21, 22, 26, 55], although different reconstruction techniques were described and performed in these investigations. Three studies used an ITB based LET as an additional procedure (375 patients, $45 \%)$, again with different types of described techniques and grafts $[1,14,50]$. One publication described a Modified Iliotibial Band Tenodesis (28 patients, 3\%) [45], as another study used a Cocker-Arnold (Modified Lemaire) procedure as their preferred LA technique (27 patients, 3\%) [58]. Five publications were RCTs (925 unique patients, 465 ACLR and 460 ACLR+LA) $[1,14,18,26$, 45] and six were prospective cohort studies (967 subjects, 592 ACLR and 375 ACLR + LA) $[15,21,22,50,55,58]$.

\section{Risk of bias}

The lateral skin incision makes it impossible to blind the patients for an extra LA procedure, inducing a performance bias risk in all RCTs [1, 14, 18, 26, 45]. By implementing the Cochrane Collaboration Tool, we

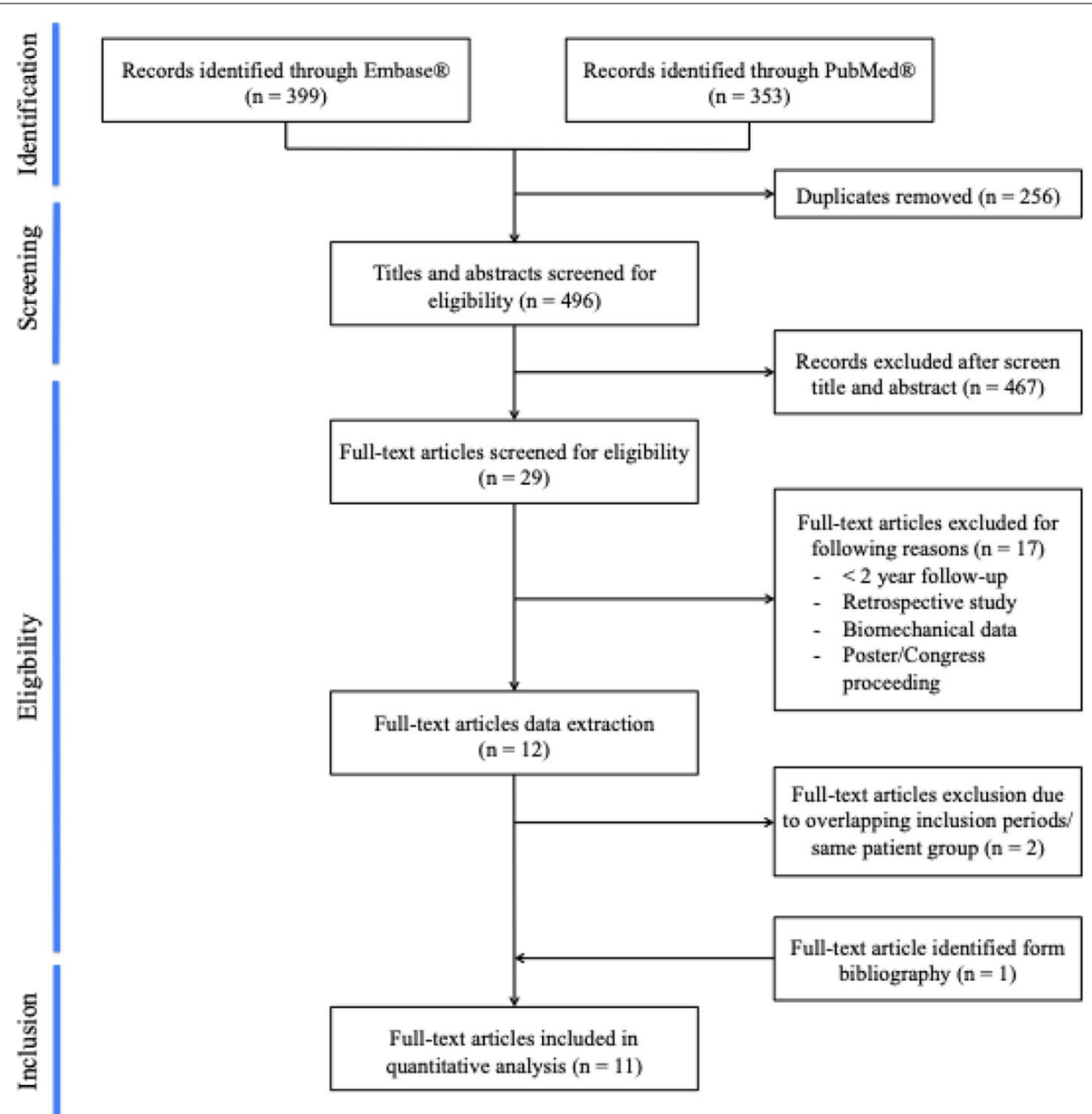

Fig. 1 Flowchart of the followed study selection procedure according to the Preferred Reporting Items for Systematic reviews and Meta-Analyses (PRISMA) criteria 


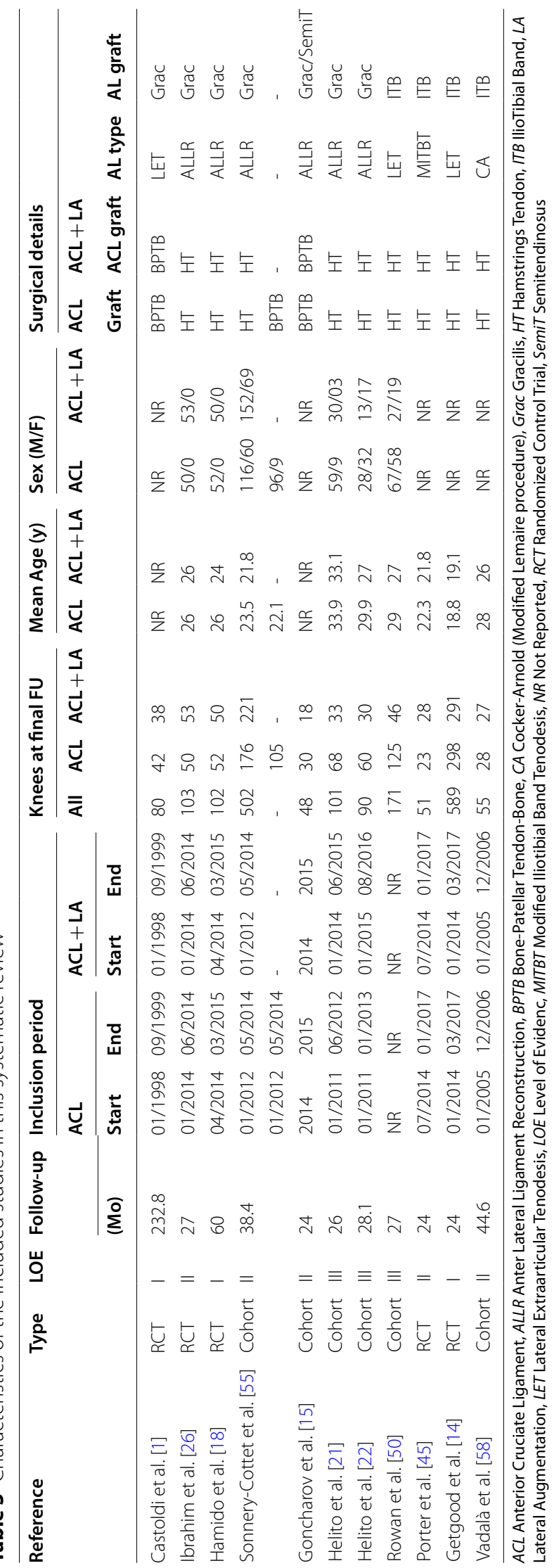


identified extra high risks on bias in publications by Castoldi et al. due to block randomization [1] and Ibrahim et al. as a result of allocation and random sequence generation based upon the date of birth of the subjects [26] (Table 4). Assessment of the prospective cohort studies $[15,21,22,50,55,58]$ using the NOS scoring system demonstrated good quality for all the included publications (Table 5).

\section{Patient reported outcome scores}

$I K D C$ : The IKDC score was reported by 10 publications (eight studies mentioned the score as continuous data $[1,14,15,21,22,45,55,58]$ with three studies making use of the 4-grade scale $[18,26,58]$. No significant difference was observed in the final IKDC scores between the isolated ACLR and the ACLR + LA procedures (Continuous data: mean difference 2.02, 95\% CI -1.01 to $5.04, \mathrm{I}^{2}=82 \%, p=0.19$ and 4 -Grade scale scoring system: OR $0.51,95 \%$ CI 0.16 to $1.67, \mathrm{I}^{2}=22 \%$, $p=0.27$ ) (Fig. 2a-b). Of note is the high observed heterogeneity in the continuous IKDC data.

Lysholm score: The postoperative Lysholm score at final follow-up was recorded in 10 publications $[1,15$, $18,21,22,26,45,50,55,58]$, with two reporting both continuous data and graded results $[18,26]$. Three Studies reported the Lysholm score as median and interquartile rage (IQR) data $[18,26,50]$ while seven studies mentioned results as Mean +-standard deviation (SD) $[1,15,21,22,45,55,58]$. The subjects treated with a

Table 4 Risk-of-bias assessment of the included Randomized Control Trails using the Cochrane Collaboration Tool

\begin{tabular}{|c|c|c|c|c|c|c|c|}
\hline Reference & $\begin{array}{l}\text { Random } \\
\text { sequence } \\
\text { generation }\end{array}$ & $\begin{array}{l}\text { Allocation } \\
\text { concealment }\end{array}$ & Selective reporting & $\begin{array}{l}\text { Other } \\
\text { sources of } \\
\text { bias }\end{array}$ & $\begin{array}{l}\text { Blinding } \\
\text { (participants and } \\
\text { personnel) }\end{array}$ & $\begin{array}{l}\text { Blinding } \\
\text { (outcome } \\
\text { assessment) }\end{array}$ & $\begin{array}{l}\text { Incomplete } \\
\text { outcome } \\
\text { data }\end{array}$ \\
\hline Castoldi et al. [1] & High Risk & Low Risk & Unclear & Unclear & High Risk & Low Risk & Low Risk \\
\hline Ibrahim et al. [26] & High Risk & High Risk & Low Risk & Unclear & High Risk & Low Risk & Low Risk \\
\hline Hamido et al. [18] & Low Risk & Low Risk & Low Risk & Unclear & High Risk & Low Risk & Low Risk \\
\hline Porter et al. [45] & Low Risk & Low Risk & Low Risk & Unclear & High Risk & Low Risk & Low Risk \\
\hline Getgood et al. [14] & Low Risk & Low Risk & Low Risk & Unclear & High Risk & Low Risk & Low Risk \\
\hline
\end{tabular}

Table 5 Risk-of-bias assessment of the included prospective cohort studies using the Newcastle-Ottawa Quality assessment Scale

\begin{tabular}{|c|c|c|c|c|c|c|c|c|c|}
\hline \multirow[t]{2}{*}{ Reference } & \multicolumn{4}{|l|}{ Selection } & \multirow[b]{2}{*}{$\begin{array}{l}\text { Comparability } \\
\text { Comparability } \\
\text { of cohorts on } \\
\text { the basis of } \\
\text { the design } \\
\text { or analysis } \\
\text { controlled for } \\
\text { confounders }\end{array}$} & \multicolumn{3}{|l|}{ Outcome } & \multirow{2}{*}{$\begin{array}{l}\text { Overall } \\
\text { Quality }\end{array}$} \\
\hline & $\begin{array}{l}\text { Representativeness } \\
\text { of the exposed } \\
\text { cohort }\end{array}$ & $\begin{array}{l}\text { Selection } \\
\text { of the non- } \\
\text { exposed } \\
\text { cohort }\end{array}$ & $\begin{array}{l}\text { Ascertainment of } \\
\text { exposure }\end{array}$ & $\begin{array}{l}\text { Demonstration } \\
\text { that outcome of } \\
\text { interest was not } \\
\text { present at start of } \\
\text { study }\end{array}$ & & $\begin{array}{l}\text { Assessment } \\
\text { of outcome }\end{array}$ & $\begin{array}{l}\text { Was } \\
\text { follow-up } \\
\text { long } \\
\text { enough for } \\
\text { outcomes } \\
\text { to occur }\end{array}$ & $\begin{array}{l}\text { Adequacy } \\
\text { of follow-up } \\
\text { of cohorts }\end{array}$ & \\
\hline $\begin{array}{l}\text { Sonnery- } \\
\text { Cottet } \\
\text { et al. [55] }\end{array}$ & $*$ & * & $*$ & * & * & * & * & * & Good \\
\hline $\begin{array}{r}\text { Goncharov } \\
\text { et al. [15] }\end{array}$ & / & * & * & * & * & * & * & * & Good \\
\hline $\begin{array}{l}\text { Helito et al. } \\
\text { [21] }\end{array}$ & * & * & * & * & * & * & * & * & Good \\
\hline $\begin{array}{l}\text { Helito et al. } \\
\text { [22] }\end{array}$ & * & * & * & * & * & * & * & $*$ & Good \\
\hline $\begin{array}{l}\text { Rowan et al. } \\
\text { [50] }\end{array}$ & $*$ & * & * & * & * & * & * & * & Good \\
\hline $\begin{array}{l}\text { Vadalà et al. } \\
\text { [58] }\end{array}$ & $*$ & * & * & * & * & * & * & * & Good \\
\hline
\end{tabular}

*: criteria met, / Criteria not met or unable to determine

Good quality: 3 or 4 stars in selection domain AND 1 or 2 stars in comparability domain AND 2 or 3 stars in outcome/exposure domain

Fair quality: 2 stars in selection domain AND 1 or 2 stars in comparability domain AND 2 or 3 stars in outcome/exposure domain

Poor quality: 0 or 1 star in selection domain OR 0 stars in comparability domain OR 0 or 1 stars in outcome/exposure domain 
combined ACLR and LA had significantly better knee function scores compared to those who underwent treatment with isolated ACLR (Continuous data: mean difference $2.86,95 \%$ CI 1.37 to $4.36, \mathrm{I}^{2}=63 \%, p<0.001$ and 4-Grade scale scoring system: OR $0.41,95 \%$ CI 0.09 to $1.96, \mathrm{I}^{2}=0 \%, p=0.26$ ) (Fig. 2c-d). Sensitivity analysis showed no difference for the estimated mean and variance of all the articles compared to those specifically reporting mean $+-\mathrm{SD}$ (mean difference $2.61,95 \% \mathrm{CI}$ 0.71 to 4.51 ).

Tegner: Six studies reported on the Tegner activity score, including four RCTs and two prospective cohort studies $[18,26,45,50,55,58]$. Three studies reported median and IQR data $[18,26,45]$, while three others used mean and SD [50, 55, 58]. No significant difference could be found in the Tegner score between patients treated with an isolated ACLR reported and those treated with a combined procedure (mean difference $0.35,95 \% \mathrm{CI}$ -0.08 to $0.78, \mathrm{I}^{2}=88 \%, p=0.11$ ) (Fig. 2e). No difference was found between the complete group and the subgroup reporting with mean $+-\mathrm{SD}$ upon sensitivity analysis (mean difference 0.28 (95\% CI -0.17 to 0.75).

\section{Graft rupture}

Graft rupture rate was reported in 10 studies [1, 14, 18, $21,22,26,45,50,55,58]$, with Ibrahim et al. reporting no re-ruptures in both groups [26]. The overall graft rupture rate was significantly lower in the ACLR + LA group (3\%) than the isolated ACLR group (12\%) (OR 0.26, 95\% CI 0.17 to $0.41, \mathrm{I}^{2}=0 \%, p<0.001$ ) (Fig. 3).

\section{Objective knee stability examinations}

Lachman Test: The Lachman test was reported in three studies (two RCTs and one cohort study) $[18,26,58]$ and reviewed in 260 knees. The frequency of negative graded tests from the included patients treated with an isolated ACLR (84\%) was not significant from those treated with a combined procedure (87\%). (OR 0.59, 95\% CI 0.11 to 3.16, $\mathrm{I}^{2}=0 \%, p=0.54$ ) (Fig. 4a).

Pivot shift test: A Pivot Shift test was reported in six studies [14, 18, 22, 26, 45, 58] including 994 knees. The results at final follow-up of the Pivot Shift test from the STABILITY trail [14] were included after contact with the first author, as they weren't separately mentioned in the publication. The frequency of positive graded tests (grade II and III) was 6\% in the group of patients treated with an ACLR and LA and 14\% in the group of patients who underwent an isolated ACLR. (OR 0.42, 95\% CI 0.26 to $0.65, \mathrm{I}^{2}=0 \%, p>0.001$ ) (Fig. $4 \mathrm{~b}$ ).

Instrumented laxity (KT-1000 Arthrometer): Sideto-side anterior translation differences, quantified by KT-1000 Arthrometer measurements, were recorded in six publications $[18,21,22,26,55,58]$, including a total of 852 knees. Three reported the difference as median and IQR data $[18,21,26]$ (two of them in combination with graded data $[18,26])$ and three other studies as Mean +-standard deviation [22, 55, 58]. Significant differences in the instrumented anterior translation was found between isolated ACLR group and the combined reconstruction group (mean difference $-0.64,95 \% \mathrm{CI}$ -1.20 to $-0.08, \mathrm{I}^{2}=94 \%, p=0.03$ ) (OR $0.10,95 \% \mathrm{CI} 0.01$ to $0.84, \mathrm{I}^{2}=0 \%, p=0.03$ ) (Fig. $4 \mathrm{c}-\mathrm{d}$ ). Sensitivity analysis didn't revealed differences when reporting as a whole group compared to subgroup of studies reporting with mean +- SD subgroup (mean difference -0.64 (95\% CI -1.20 to -0.08$)$.

\section{Return to play}

Return to the same level of play was recorded in five publications $[1,15,18,50,55]$. No significant difference was noted in the return to play between the patients who underwent an isolated ACLR (68\%) and those who were treated with an ACLR + LA (74\%) (mean difference 1.47, $95 \%$ CI 0.99 to $2.19, \mathrm{I}^{2}=4 \%, p=0.06$ ). (Fig. 5). Of note, one study, which included only male athletes, reported a $100 \%$ return to sports in both groups [18].

\section{Discussion}

The most important finding of our systematic review is that the addition of a LA to a primary ACLR results in significant reductions in graft failure and persistent rotatory laxity at a minimum of two years post operatively. The identification of generally superior patient reported outcome scores and a higher proportion of return to sport in patients treated with an ACLR + LA adds further weight to the argument that contemporary LA techniques should be considered when treating ACL injured patients who are deemed at high risk of graft failure.

Our hypothesis of ACL + LA procedures providing superior objective and clinical outcomes is generally supported, particularly in regard to rotational stability testing, as determined by the Pivot Shift test. Clinical and biomechanical insights have evolved over the past decade regarding the ALC as a rotatory stabilizer in ACL deficient and reconstructed knees. Ferretti et al. described that in up to $90 \%$ of ACL injured knees, additional lesions were found to the lateral structures [9]. Inferior clinical results were noted by Sobrado et al. when comparing patients with ACL reconstructed knees and concomitant, but untreated ALL lesions to patients treated for isolated ACL ruptures with intact lateral structures [52]. These clinical studies are supported by overwhelming biomechanical data regarding the role of the ALC as a more efficient lever arm 


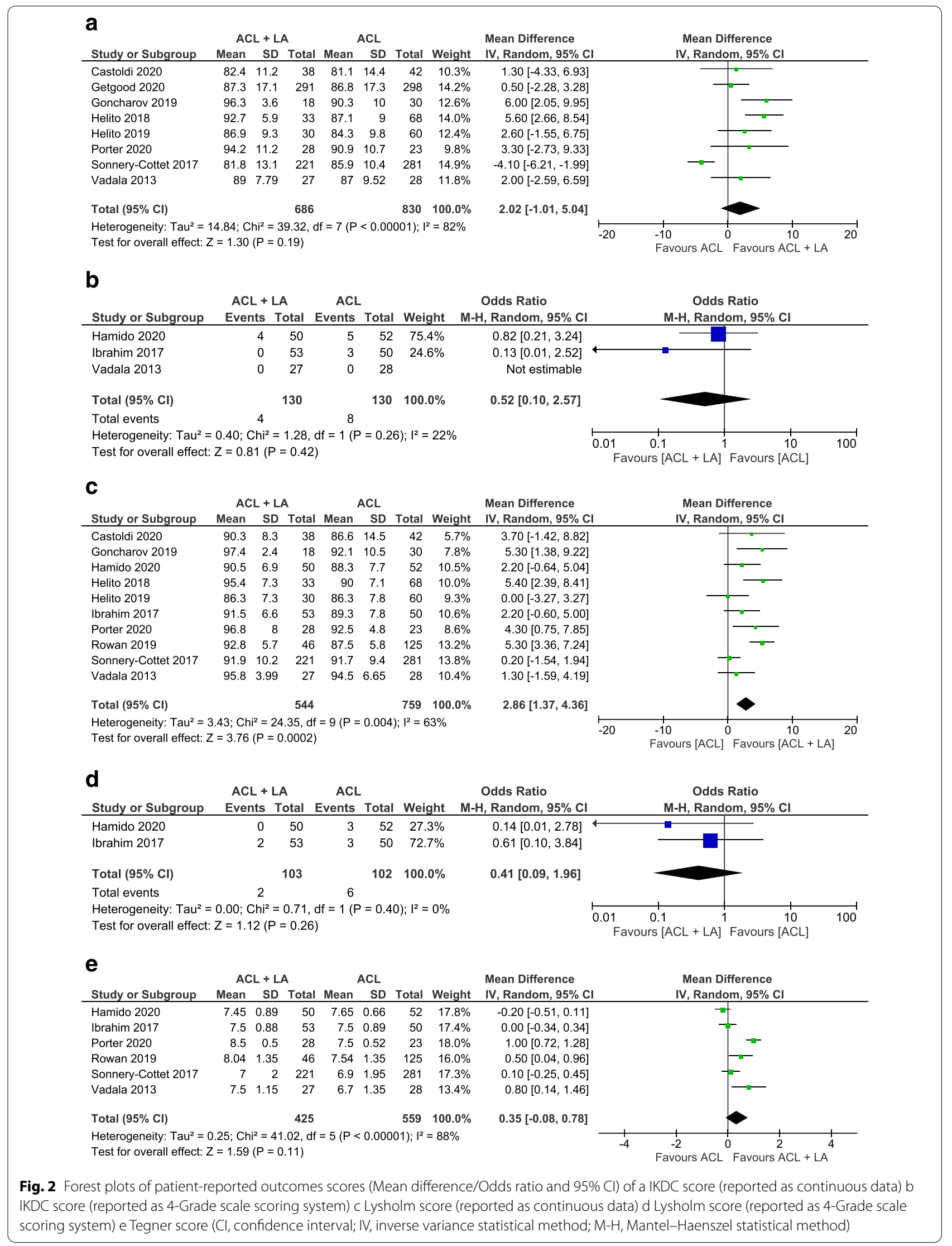




\begin{tabular}{|c|c|c|c|c|c|c|c|c|c|}
\hline Study or Subgroup & \multicolumn{2}{|c|}{$A C L+L A$} & \multicolumn{2}{|c|}{$\mathrm{ACL}$} & Weight & $\begin{array}{c}\text { Odds Ratio } \\
\text { M-H, Random, } 95 \% \mathrm{CI}\end{array}$ & \multicolumn{3}{|c|}{$\begin{array}{c}\text { Odds Ratio } \\
\mathrm{M}-\mathrm{H}, \text { Random, } 95 \% \mathrm{Cl}\end{array}$} \\
\hline Castoldi 2020 & 5 & 38 & 12 & 42 & $14.0 \%$ & $0.38[0.12,1.20]$ & & & \\
\hline Getgood 2020 & 11 & 291 & 34 & 298 & $38.0 \%$ & $0.31[0.15,0.61]$ & & & \\
\hline Hamido 2020 & 0 & 50 & 5 & 52 & $2.2 \%$ & $0.09[0.00,1.59]$ & & & \\
\hline Helito 2018 & 0 & 33 & 5 & 68 & $2.2 \%$ & $0.17[0.01,3.21]$ & & & \\
\hline Helito 2019 & 1 & 30 & 13 & 60 & $4.3 \%$ & $0.12[0.02,1.00]$ & & & \\
\hline Ibrahim 2017 & 0 & 53 & 0 & 50 & & Not estimable & & & \\
\hline Porter 2020 & 0 & 28 & 4 & 23 & $2.1 \%$ & $0.08[0.00,1.49]$ & & & \\
\hline Rowan 2019 & 0 & 46 & 13 & 125 & $2.3 \%$ & $0.09[0.01,1.54]$ & & & \\
\hline Sonnery-Cottet 2017 & 9 & 221 & 37 & 281 & $33.0 \%$ & $0.28[0.13,0.59]$ & $\longrightarrow$ & & \\
\hline Vadala 2013 & 0 & 27 & 2 & 28 & $2.0 \%$ & $0.19[0.01,4.21]$ & & & \\
\hline Total $(95 \% \mathrm{Cl})$ & & 817 & & 1027 & $100.0 \%$ & $0.26[0.17,0.41]$ & & & \\
\hline Total events & 26 & & 125 & & & & & & \\
\hline $\begin{array}{l}\text { Heterogeneity: } \mathrm{Tau}^{2}= \\
\text { Test for overall effect: }\end{array}$ & $\begin{array}{l}.00 ; \mathrm{Chi}^{2} \\
=6.04(\mathrm{~F}\end{array}$ & $\begin{array}{l}=3.08, \\
<0.00\end{array}$ & $\begin{array}{l}\mathrm{df}=8(\mathrm{P} \\
001)\end{array}$ & $=0.93$ & $;\left.\right|^{2}=0 \%$ & & $\begin{array}{ll}0.01 & 0.1 \\
& \text { Favours }[\mathrm{ACL}+\mathrm{LA}\end{array}$ & $\begin{array}{cc}1 & 10 \\
& \text { Favours }[\mathrm{ACL}]\end{array}$ & 100 \\
\hline
\end{tabular}

to control the rotatory translation when compared to an isolated ACLR [11, 32, 39, 56]. Subsequently, several philosophies and techniques have emerged over the past decade in an attempt to restore the anatomy and/ or function of the ALC.

Reconstruction of the ALL, a fibrous band in the anterolateral capsule initially identified by Segond, has been described in a number of different forms. These aim to be as anatomic as possible; however, different descriptions of the anatomy of the ALL has led to a variation in ALL graft insertion points, particularly in relation to its tibial insertion most recently. The original technique developed by Claes utilised a single graft coursing anterior and distal to the lateral collateral ligament femoral insertion to a position midway between the fibula head and Gerdy's tubercle on the tibia. Later single graft procedures popularised by Helito et al. [20] have been revised to a more posterior and proximal position on the femur with a similar tibial insertion to obtain the functional anisometry in the ALLR graft [27]. The reconstruction developed by Sonnery-Cottet et al. [53] has used the same femoral origin but uses a wider footprint insertion on the tibia creating a double graft structure tensioned in extension. Even with these variations in technique, the results seem to speak for themselves. The addition of the ALLR seems to reduce rotatory laxity and graft failure.

An alternative approach in the effort to improve the rotational stability of intra-articular ACLR, are the different types of modified LETs, derived from abandoned 'historical' isolated extra-articular tenodeses [51]. The common feature of these techniques is the addition of a lateral soft tissue restraint on a certain distance from the central pivot of the knee [30]. Unlike the ALLR, these non-anatomical reconstructions are roughly isometric throughout the range of motion, aiming to restore the function of the several lateral structures of the ALC that are involved in the rotatory stabilization of the knee [11, 32, 41].

Although on-going controversy remains if a specific type of LA is superior [47], the results of our systematic review demonstrate that adding either an ALL reconstruction or LET procedure significantly improves the rotatory stability, which is consistent with previous published systematic reviews and metaanalyses $[4,7,23,48]$.

The pooled data for the anterior stability tests did not show a significant difference between isolated or combined ACLR procedures when performed manually with the Lachman Test. However, the addition of the LA procedure appears to limit the extreme antero-posterior translation, as observed with the significant reduction in the side-to-side differences measured with the KT-1000 Arthrometer testing. This may indicate that an isolated ACLR is able to control antero-posterior translation and maybe sufficient in the treatment of ACL deficient knees when significant rotator laxity is not present. However, this also may point to the potential benefit of LA in reducing ACL graft strain as seen in a cadaveric studies by Engebretsen et al. [8] and more recently by Marom et al. [37], identifying a significant reduction in graft forces when a LET type augmentation was added to an ACLR. This may also account for the significant reduction in graft re-rupture rates in the combined group that were observed. Possible explanations are the superior rotational stability with the added LA, but also by the perceived load-sharing effect of a LA in combination of an intra-articular ACLR. Adding a LA might reduce the deformity of the graft during the early ligamentization process, promoting final graft strength and subsequent reduced graft failure [44]. This is supported 


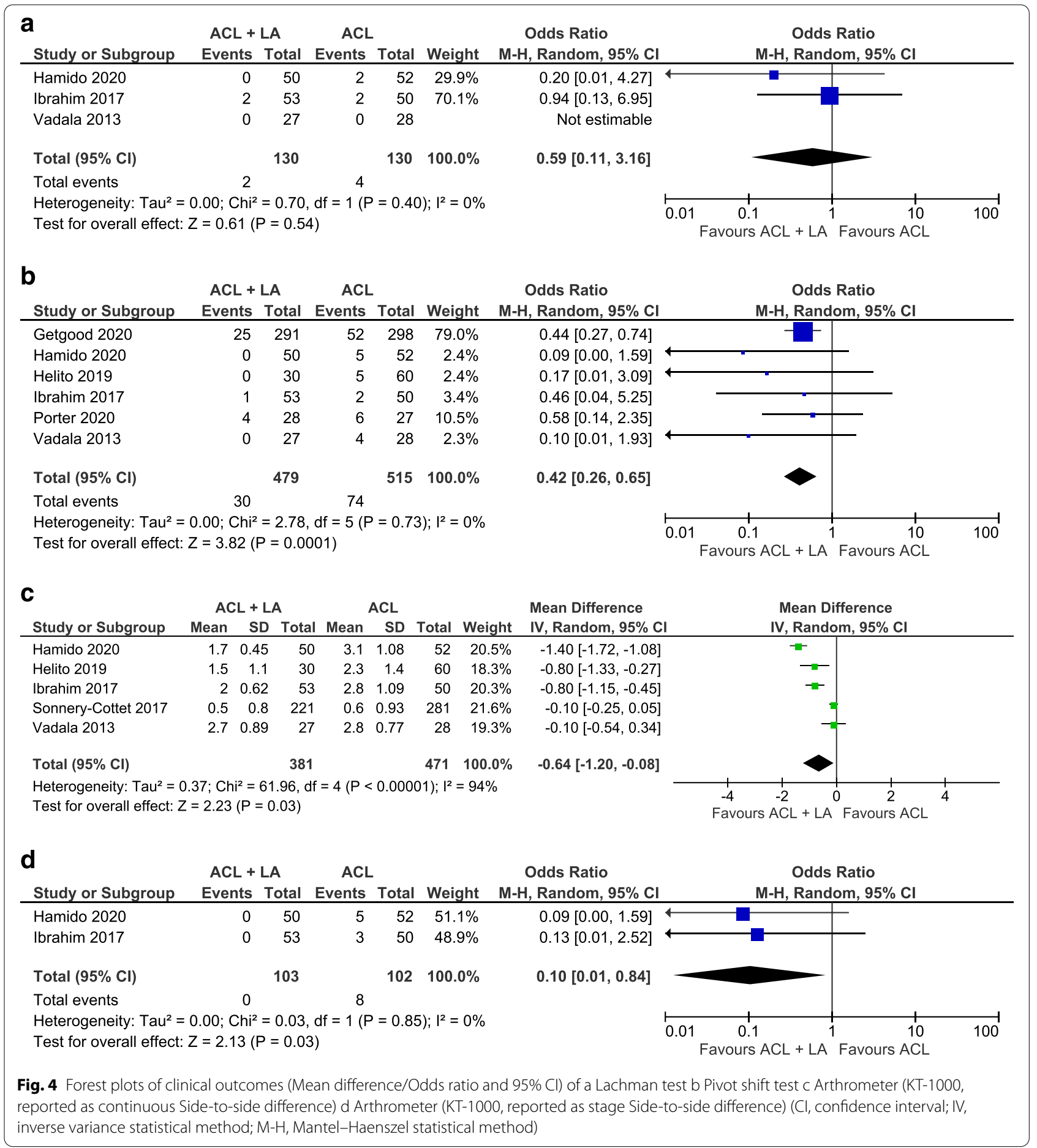

by a recent publication by Cavaignac et al., identifying better maturation and incorporation of 4-strand hamstrings ACL grafts at the 1 year interval when combined with a LA as observed on MRI [3].

Some discrepancy exists regarding the patient reported outcome scores, and more specifically concerning the dedicated knee scores. No significant differences could be found between the ACLR and ACLR + LA groups when reviewing the IKDC scores. Conversely, the Lysholm score showed a significant improvement in the combined treated group. This may suggest that the Lysholm score could be better at 


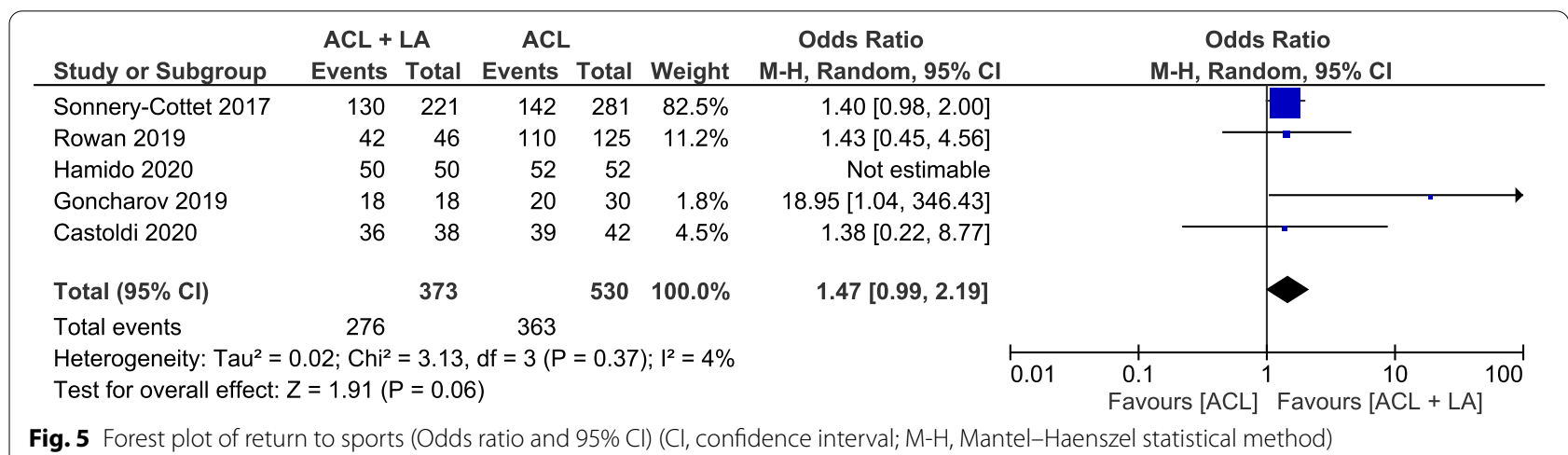

picking up differences in outcomes specifically related to rotatory laxity. However, it is challenging to draw conclusions due to the significant heterogeneity that was observed when pooling the IKDC and Lysholm scores, similar to previous published systematic reviews $[4,23,62]$. Possible explanations for this are the high variability between studies regarding type of ACLR and LA procedures as well as the included patient characteristics. On the other hand, $\mathrm{Xu}$ et al. [62] reported similar heterogeneity although their systematic review included only ALL reconstructions, indicating a possible inherent effect of the scoring system on these results. No significant differences were observed between the two groups regarding the activity related Tegner score.

One study identified an initial delay in the recovery in the ACLR + LA combined groups due to a higher amount of pain along with a delayed recovery in quadriceps strength, resulting in initial reduced subjective outcomes when compared to isolated ACLR patients [14]. This delay was attributed to the additional lateral procedure but proved to be transient as the differences resolved by the 6 months postoperative review [13]. Our results indicate that at minimum 2 years follow up, patients treated with a combined procedure have equivalent to superior outcomes, which is consistent with recent systematic reviews [4, 62], but deviates from older reviews $[7,23,48]$. Possible explanations for these superior results are the improved knee rotatory stability with the newer, more dedicated LA procedures along with the observed equivalent isokinetic muscle recovery in patients treated with ACLR + LA [13, 28]. These findings are also likely the reason of the higher, although not significant, degree of return to sports observed in the ACLR + LA treated group. After completing full rehabilitation, better objective rotational stability and subjective functional outcomes tend to promote a higher return to sports.
Our systematic review is characterized by a number of limitations, which must be considered when interpreting the findings. First, the specific inclusion of all types of ACLR and LA allows for great variability in surgical techniques and graft choices. The inclusion of different patient populations, indications, and differing treatment of concomitant meniscal and cartilage lesions as well as lack of standardised post-operative rehabilitation, may also create a significant selection bias. However, this also speaks to the generalizability of the findings to a wider patient population. Furthermore, it was the author's intention to include any type of LA, as we wanted to evaluate the clinical effect of an additional lateral procedure in ACLR, independent from their different surgical techniques. Second, our choice to include only studies from 2012 onwards seems arbitrary but is based on the LA's renaissance with the 'rediscovery' of the ALL. New techniques and surgical indications have emerged since these publications. By choosing this date, we intended to include studies that would be influenced by these new insights utilising contemporary techniques in current clinical practice. Unfortunately, choosing this restricted inclusion time period meant that some long-term follow-up studies by surgeons who were early advocates of the concept of a LA procedure, are not included in this systematic review $[10,38,63]$. Finally, we did not address the possible adverse events and consequences of an additional LA procedure, as only a limited number of studies reported on specific issues related to the LA [14, 18, 55]. Only one, underpowered study mentioned longterm radiographic follow-up for lateral tibiofemoral osteoarthritis [1].

Even in the face of this compelling data, routine implementation of any type of LA in primary ACLR remains controversial as insights continue to evolve around the indications and surgical techniques. Several high-level 
RCTs regarding LA procedures with different types of intra-articular grafts are highly anticipated (Stability 2 (ClinicalTrails.gov identifier NCT03935750), SANTI RCT (NCT03740022)) and might provide further insights on the indications for LA procedures. For now, young age $(<25)$, return to pivoting contact sports and the use of a hamstring autograft are indications for LA of primary ACLR in our practice. The presence of knee hyperextension, meniscal deficiency and increased tibial slope, even when using other grafts such as bone patella tendon bone, are considerations for the addition of a LA. Due to the known inferior results associated with revision ACLR, the majority of revisions are augmented by an LET in our practice.

New prospective research will need to focus on the identification of patients at risk of inferior results and higher re-rupture rates when treated with an isolated ACLR. Further individualisation of the treatment approach will be necessary to optimize patient important outcomes.

\section{Conclusion}

Conflicting anatomic and biomechanical data surrounding the ALC, amplified by differences of opinion in the surgical community, has led to controversy surrounding the use of LA procedures in primary ACLR. Based upon this systematic review of contemporary clinical literature, and findings from previously performed systematic reviews $[4,7,23,48,62]$, the addition of a LA to primary ACLR can significantly reduce the risk of graft rupture and persistent rotatory laxity, without jeopardizing patient reported outcomes. Future research will focus on when to add these procedures, not if.

\footnotetext{
Abbreviations

ACL: Anterior cruciate ligament; ACLR: Anterior cruciate ligament reconstruction; ALC: Anterolateral complex; ALL: Anterolateral ligament; ALLR: Anterolateral ligament reconstruction; BPTB: Bone-patellar tendon-bone; $\mathrm{Cl}$ : Confidence interval; HT: Hamstrings tendon; ITB: Iliotibial band; IQR: Interquartile range; IV: Inverse variance (statistical method); LA: Lateral augmentation; LET: Lateral extra-articular tenodesis; M-H: Mantel-Haenszel (statistical method); OR: Odds ratio; NOS: Newcastle-Ottawa Scale; PRISMA: Preferred reporting items for systematic reviews and meta-analyses; RCT: Randomised Control Trail; SD: Standard deviation.

\section{Acknowledgements}

None.

\section{Authors' contributions}

All listed authors have contributed substantially to this work. LB and TV contributed equally to this work. LB: Designed the study, data screening and extraction, data interpretation, tables and figures, manuscript writing. TV: Data screening and extraction, data interpretation, manuscript editing. AF: Data interpretation, statistical analysis, tables and figures, manuscript editing. AMJG: Designed the study, data interpretation, manuscript editing. All the authors read and approved the final manuscript.
}

Funding

This research did not receive any specific grant from funding agencies in the public, commercial, or not for-profit sectors.

\section{Availability of data and materials}

Data obtained during the literature review by the independent authors are available upon request.

\section{Declarations}

Ethics approval and consent to participate

No ethical approval necessary, systematic review.

\section{Consent for publication}

No consent necessary.

\section{Competing interests}

$\mathrm{LB}$ or any member of his or her immediate family has no funding or commercial associations that might pose a conflict of interest in connection with the submitted article.TV or any member of his or her immediate family has no funding or commercial associations that might pose a conflict of interest in connection with the submitted article.AF or any member of his or her immediate family has no funding or commercial associations that might pose a conflict of interest in connection with the submitted article.AMJG is a consultant for Smith \& Nephew and receives research support from Smith \& Nephew and Ossür. There is no conflict of interest with the submitted article.

\section{Author details}

${ }^{1}$ Department of Orthopedic Surgery, Fowler Kennedy Sport Medicine Clinic, University of Western Ontario, 3M Centre, 1151 Richmond Street, London, ON N6A 3K7, Canada. ${ }^{2}$ Health and Rehabilitation Sciences, Faculty of Health Sciences, University of Western Ontario, 3M Centre, 1151 Richmond Street, London, ON N6A 3K7, Canada.

Received: 22 April 2021 Accepted: 24 June 2021

Published online: 12 August 2021

\section{References}

1. Castoldi M, Magnussen RA, Gunst S, Batailler C, Neyret P, Lustig S, Servien E (2020) A randomized controlled trial of bone-patellar tendon-bone anterior cruciate ligament reconstruction with and without lateral extra-articular tenodesis: 19-year clinical and radiological follow-up. Am J Sports Med 48(7):1665-1672

2. Caterine S, Litchfield R, Johnson M, Chronik B, Getgood A (2015) A cadaveric study of the anterolateral ligament: re-introducing the lateral capsular ligament. Knee Surg Sports Traumatol Arthrosc 23(11):3186-3195

3. Cavaignac E, Mesnier T, Marot V, Fernandez A, Faruch M, Berard E, Sonnery-Cottet B (2020) Effect of lateral extra-articular tenodesis on anterior cruciate ligament graft incorporation. Orthop J Sports Med 8(11):2325967120960097

4. Cheng X, Liu F, Liu F, Zhou D, Paulus AC (2020) Surgical intra- and extraarticular anterior cruciate ligament reconstruction: a meta-analysis. BMC Musculoskelet Disord 21(1):414

5. Claes S, Vereecke E, Maes M, Victor J, Verdonk P, Bellemans J (2013) Anatomy of the anterolateral ligament of the knee. J Anat 223(4):231-238

6. Delaloye J-R, Hartog C, Blatter S, Schläppi M, Müller D, Denzler D, Murar J, Koch PP (2020) Anterolateral ligament reconstruction and modified lemaire lateral extra-articular tenodesis similarly improve knee stability after anterior cruciate ligament reconstruction: a biomechanical study. Arthroscopy 36(7):1942-1950

7. Devitt BM, Bell SW, Ardern CL, Hartwig T, Porter TJ, Feller JA, Webster KE (2017) The role of lateral extra-articular tenodesis in primary anterior cruciate ligament reconstruction: a systematic review with meta-analysis and best-evidence synthesis. Orthop J Sports Med 5(10):2325967117731767

8. Engebretsen L, Lew WD, Lewis JL, Hunter RE (1990) The effect of an iliotibial tenodesis on intraarticular graft forces and knee joint motion. Am J Sports Med 18(2):169-176 
9. Ferretti A, Monaco E, Fabbri M, Maestri B, de Carli A (2017) Prevalence and classification of injuries of anterolateral complex in acute anterior cruciate ligament tears. Arthroscopy 33(1):147-154

10. Ferretti A, Monaco E, Ponzo A, Basiglini L, lorio R, Caperna L, Conteduca $F$ (2016) Combined intra-articular and extra-articular reconstruction in anterior cruciate ligament-deficient knee: 25 years later. Arthroscopy 32(10):2039-2047

11. Geeslin AG, Chahla J, Moatshe G, Muckenhirn KJ, Kruckeberg BM, Brady AW, Coggins A, Dornan GJ, Getgood AM, Godin JA, LaPrade RF (2018) Anterolateral knee extra-articular stabilizers: a robotic sectioning study of the anterolateral ligament and distal iliotibial band kaplan fibers. Am J Sports Med 46(6):1352-1361

12. Getgood A, Brown C, Lording T, Amis A, Claes S, Geeslin A, MusahI V (2019) The anterolateral complex of the knee: results from the International ALC Consensus Group Meeting. Knee Surg Sports Traumatol Arthrosc 27(1):166-176

13. Getgood A, Hewison C, Bryant D, Litchfield R, Heard M, Buchko G, Hiemstra LA, Willits KR, Firth A, MacDonald P (2020) No difference in functional outcomes when lateral extra-articular tenodesis is added to anterior cruciate ligament reconstruction in young active patients: the stability study. Arthroscopy 36(6):1690-1701

14. Getgood AMJ, Bryant DM, Litchfield R, Heard M, McCormack RG, Rezansoff A, Peterson D, Bardana D, MacDonald PB, Verdonk PCM, Spalding T, Willits K, Birmingham T, Hewison C, Wanlin S, Firth A, Pinto R, Martindale A, O'Neill L, Jennings M, Daniluk M, Boyer D, Zomar M, Moon K, Pritchett R, Payne K, Fan B, Mohan B, Buchko GM, Hiemstra LA, Kerslake S, Tynedal J, Stranges G, Mcrae S, Gullett L, Brown H, Legary A, Longo A, Christian M, Ferguson C, Mohtadi N, Barber R, Chan D, Campbell C, Garven A, Pulsifer K, Mayer M, Simunovic N, Duong A, Robinson D, Levy D, Skelly M, Shanmugaraj A, Howells F, Tough M, Spalding T, Thompson P, Metcalfe A, Asplin L, Dube A, Clarkson L, Brown J, Bolsover A, Bradshaw C, Belgrove L, Millan F, Turner S, Verdugo S, Lowe J, Dunne D, McGowan K, Suddens C-M, Declerca G, Vuylsteke K, van Haver M (2020) Lateral extra-articular tenodesis reduces failure of hamstring tendon autograft anterior cruciate ligament reconstruction: 2-year outcomes from the STABILITY study randomized clinical trial. Am J Sports Med 48(2):285-297

15. Goncharov EN, Koval OA, Dubrov VE, Bezuglov EN, Filimonova AM, Goncharov NG (2019) Clinical experience with combined reconstruction of the anterior cruciate and anterolateral ligaments of the knee in sportsmen. Int Orthop 43(12):2781-2788

16. Grassbaugh JA, Turner EK (2019) Editorial Commentary: anatomy of the anterolateral ligament of the knee-the science of looking for bigfoot. Arthroscopy 35(2):682-683

17. Grassi A, Macchiarola L, Lucidi GA, Silvestri A, Dal Fabbro G, Marcacci M, Zaffagnini S (2021) Ten-year survivorship, patient-reported outcome measures, and patient acceptable symptom state after over-the-top hamstring anterior cruciate ligament reconstruction with a lateral extraarticular reconstruction: analysis of 267 consecutive cases. Am J Sports Med 49(2):374-383

18. Hamido F, Habiba AA, Marwan Y, Soliman ASI, Elkhadrawe TA, Morsi MG, Shoaeb W, Nagi A (2020) Anterolateral ligament reconstruction improves the clinical and functional outcomes of anterior cruciate ligament reconstruction in athletes. Knee Surg Sports Traumatol Arthrosc 29(4):1173-1180

19. Hefti E, Müller W, Jakob RP, Stäubli HU (1993) Evaluation of knee ligament injuries with the IKDC form. Knee Surg Sports Traumatol ArthrosC 1(3-4):226-234

20. Helito CP, Bonadio MB, Gobbi RG, da Mota e Albuquerque RF, Pécora JR, Camanho GL, Demange MK (2015) Combined intra- and extra-articular reconstruction of the anterior cruciate ligament: the reconstruction of the knee anterolateral ligament. Arthrosc Tech 4(3):e239-e244

21. Helito CP, Camargo DB, Sobrado MF, Bonadio MB, Giglio PN, Pécora JR, Camanho GL, Demange MK (2018) Combined reconstruction of the anterolateral ligament in chronic ACL injuries leads to better clinical outcomes than isolated ACL reconstruction. Knee Surg Sports Traumatol Arthrosc 26(12):3652-3659

22. Helito CP, Sobrado MF, Giglio PN, Bonadio MB, Pécora JR, Camanho GL, Demange MK (2019) Combined reconstruction of the anterolateral ligament in patients with anterior cruciate ligament injury and ligamentous hyperlaxity leads to better clinical stability and a lower failure rate than isolated anterior cruciate ligament reconstruction. Arthroscopy 35(9):2648-2654
23. Hewison CE, Tran MN, Kaniki N, Remtulla A, Bryant D, Getgood AM (2015) Lateral extra-articular tenodesis reduces rotational laxity when combined with anterior cruciate ligament reconstruction: a systematic review of the literature. Arthroscopy 31(10):2022-2034

24. Higgins JPT, Altman DG, Gøtzsche PC, Jüni P, Moher D, Oxman AD, Savović J, Schulz KF, Weeks L, Sterne JAC (2011) The Cochrane Collaboration's tool for assessing risk of bias in randomised trials. BMJ 343:d5928

25. Higgins JPT, Thompson SG (2002) Quantifying heterogeneity in a metaanalysis. Stat Med 21(11):1539-1558

26. Ibrahim SA, Shohdy EM, Marwan Y, Ramadan SA, Almisfer AK, Mohammad MW, Abdulsattar WS, Khirat S (2017) Anatomic reconstruction of the anterior cruciate ligament of the knee with or without reconstruction of the anterolateral ligament: a randomized clinical trial. Am J Sports Med 45(7):1558-1566

27. Imbert P, Lutz C, Daggett M, Niglis L, Freychet B, Dalmay F, Sonnery-Cottet B (2016) Isometric characteristics of the anterolateral ligament of the knee: a cadaveric navigation study. Arthroscopy 32(10):2017-2024

28. Joseph L, Demey G, Chamu T, Schmidt A, Germain A, van Rooij F, Saffarini M, Dejour D (2020) Adding a modified Lemaire procedure to ACLR in knees with severe rotational knee instability does not compromise isokinetic muscle recovery at the time of return-to-play. J Exp Orthop 7(1):84

29. Kennedy MI, LaPrade CM, Geeslin AG, LaPrade RF (2018) An overview of clinically relevant biomechanics of the anterolateral structures of the knee. Tech Ortho 33(4):213-218

30. Kittl C, Halewood C, Stephen JM, Gupte CM, Weiler A, Williams A, Amis AA (2015) Length change patterns in the lateral extra-articular structures of the knee and related reconstructions. Am J Sports Med 43(2):354-362

31. Kosy JD, Mandalia VI, Anaspure R (2015) Characterization of the anatomy of the anterolateral ligament of the knee using magnetic resonance imaging. Skeletal Radiol 44(11):1647-1653

32. Lagae KC, Robberecht J, Athwal KK, Verdonk PCM, Amis AA (2020) ACL reconstruction combined with lateral monoloop tenodesis can restore intact knee laxity. Knee Surg Sports Traumatol Arthrosc 28(4):1159-1168

33. LaPrade RF (2016) Editorial Commentary: Defining the anatomy of the anterolateral aspect of the knee among experts is clearly needed. Arthroscopy 32(5):842-843

34. Levy BA, Sabbag OD (2017) Editorial Commentary: Is anterolateral ligament reconstruction of the knee needed? The debate rages on. Arthroscopy 33(8):1584-1586

35. Liberati A, Altman DG, Tetzlaff J, Mulrow C, Gøtzsche PC, loannidis JPA, Clarke M, Devereaux PJ, Kleijnen J, Moher D (2009) The PRISMA statement for reporting systematic reviews and meta-analyses of studies that evaluate healthcare interventions: explanation and elaboration. BMJ 339:b2700

36. Lysholm J, Gillquist J (1982) Evaluation of knee ligament surgery results with special emphasis on use of a scoring scale. Am J Sports Med 10(3):150-154

37. Marom N, Ouanezar H, Jahandar H, Zayyad ZA, Fraychineaud T, Hurwit D, Imhauser CW, Wickiewicz TL, Pearle AD, Nawabi DH (2020) Lateral extraarticular tenodesis reduces anterior cruciate ligament graft force and anterior tibial translation in response to applied pivoting and anterior drawer loads. Am J Sports Med 48(13):3183-3193

38. Meynard P, Pelet H, Angelliaume A, Legallois Y, Lavignac P, de Bartolo R, Fabre T, Costes S (2020) ACL reconstruction with lateral extra-articular tenodesis using a continuous graft: 10-year outcomes of 50 cases. Orthop Traumatol Surg Res 106(5):929-935

39. Monaco E, Fabbri M, Mazza D, Daggett M, Redler A, Lanzetti RM, de Carli A, Ferretti A (2018) The effect of sequential tearing of the anterior cruciate and anterolateral ligament on anterior translation and the pivotshift phenomenon: a cadaveric study using navigation. Arthroscopy 34(4):1009-1014

40. Musahl V, Herbst E, Burnham JM, Fu FH (2018) The anterolateral complex and anterolateral ligament of the knee. J Am Acad Orthop Surg 26(8):261-267

41. Neri T, Dabirrahmani D, Beach A, Grasso S, Putnis S, Oshima T, Cadman J, Devitt B, Coolican M, Fritsch B, Appleyard R, Parker D (2021) Different anterolateral procedures have variable impact on knee kinematics and stability when performed in combination with anterior cruciate ligament reconstruction. J ISAKOS 6(2):74-81

42. Noyes FR, Huser LE, West J, Jurgensmeier D, Walsh J, Levy MS (2018) Two different knee rotational instabilities occur with anterior cruciate ligament and anterolateral ligament injuries: a robotic study on anterior 
cruciate ligament and extra-articular reconstructions in restoring rotational stability. Arthroscopy 34(9):2683-2695

43. Parisien RL (2020) Editorial Commentary: The epic saga of the anterior cruciate ligament and anterolateral complex of the knee-loyal sidekick may provide protection without constraint. Arthroscopy 36(5):1374-1375

44. Pernin J, Verdonk P, Si Selmi TA, Massin P, Neyret P (2010) Long-term follow-up of 24.5 years after intra-articular anterior cruciate ligament reconstruction with lateral extra-articular augmentation. Am J Sports Med 38(6):1094-1102

45. Porter M, Shadbolt B (2020) Modified iliotibial band tenodesis is indicated to correct intraoperative residual pivot shift after anterior cruciate ligament reconstruction using an autologous hamstring tendon graft: a prospective randomized controlled trial. Am J Sports Med 48(5):1069-1077

46. Pula DA (2019) Editorial Commentary: The anterolateral ligament really exists, now show me how to find it. Arthroscopy 35(2):528-529

47. Ra HJ, Kim J-H, Lee D-H (2020) Comparative clinical outcomes of anterolateral ligament reconstruction versus lateral extra-articular tenodesis in combination with anterior cruciate ligament reconstruction: systematic review and meta-analysis. Arch Orthop Trauma Surg 104(7):923-931

48. Rezende FC, de Moraes VY, Martimbianco ALC, Luzo MV, da Silveira Franciozi CE, Belloti JC (2015) Does combined intra- and extraarticular $\mathrm{ACL}$ reconstruction improve function and stability? a meta-analysis. Clin Orthop Relat Res 473(8):2609-2618

49. Rossi MJ (2019) Editorial commentary: Anterolateral ligament augmentation for the anterior cruciate ligament-deficient knee debate- the proof is in the pudding. Arthroscopy 35(3):893-895

50. Rowan FE, Huq SS, Haddad FS (2019) Lateral extra-articular tenodesis with $\mathrm{ACL}$ reconstruction demonstrates better patient-reported outcomes compared to $\mathrm{ACL}$ reconstruction alone at 2 years minimum follow-up. Arch Orthop Trauma Surg 139(10):1425-1433

51. Slette EL, Mikula JD, Schon JM, Marchetti DC, Kheir MM, Turnbull TL, LaPrade RF (2016) Biomechanical results of lateral extra-articular tenodesis procedures of the knee: a systematic review. Arthroscopy 32(12):2592-2611

52. Sobrado MF, Giglio PN, Bonadio $M B$, Helito PVP, Guimarães TM, Pécora JR, Gobbi RG, Helito CP (2020) Outcomes after isolated acute anterior cruciate ligament reconstruction are inferior in patients with an associated anterolateral ligament injury. Am J Sports Med 48(13):3177-3182

53. Sonnery-Cottet B, Daggett M, Helito CP, Fayard J-M, Thaunat M (2016) Combined anterior cruciate ligament and anterolateral ligament reconstruction. Arthrosc Tech 5(6):e1253-e1259

54. Sonnery-Cottet B, Saithna A, Blakeney WG, Ouanezar H, Borade A, Daggett M, Thaunat M, Fayard JM, Delaloye JR (2018) Anterolateral ligament reconstruction protects the repaired medial meniscus: a comparative study of 383 anterior cruciate ligament reconstructions from the SANTI Study Group with a minimum follow-up of 2 years. Am J Sports Med 46(8):1819-1826
55. Sonnery-Cottet B, Saithna A, Cavalier M, Kajetanek C, Temponi EF, Daggett M, Helito CP, Thaunat M (2017) Anterolateral ligament reconstruction is associated with significantly reduced $\mathrm{ACL}$ graft rupture rates at a minimum follow-up of 2 years: a prospective comparative study of 502 patients from the SANTI Study Group. Am J Sports Med 45(7):1547-1557

56. Spencer L, Burkhart TA, Tran MN, Rezansoff AJ, Deo S, Caterine S, Getgood AM (2015) Biomechanical analysis of simulated clinical testing and reconstruction of the anterolateral ligament of the knee. Am J Sports Med 43(9):2189-2197

57. Tegner Y, Lysholm J (1985) Rating systems in the evaluation of knee ligament injuries. Clin Orthop Relat Res 189:43-49

58. Vadalà AP, lorio R, de Carli A, Bonifazi A, lorio C, Gatti A, Rossi C, Ferretti A (2013) An extra-articular procedure improves the clinical outcome in anterior cruciate ligament reconstruction with hamstrings in female athletes. Int Orthop 37(2):187-192

59. Vincent J-P, Magnussen RA, Gezmez F, Uguen A, Jacobi M, Weppe F, AlSaati MF, Lustig S, Demey G, Servien E, Neyret P (2012) The anterolateral ligament of the human knee: an anatomic and histologic study. Knee Surg Sports Traumatol Arthrosc 20(1):147-152

60. Wan X, Wang W, Liu J, Tong T (2014) Estimating the sample mean and standard deviation from the sample size, median, range and/or interquartile range. BMC Med Res Methodol 14:135

61. Weber AE, Zuke W, Mayer EN, Forsythe B, Getgood A, Verma NN, Bach BR, Bedi A, Cole BJ (2019) Lateral augmentation procedures in anterior cruciate ligament reconstruction: anatomic, biomechanical, imaging, and clinical evidence. Am J Sports Med 47(3):740-752

62. Xu C, Chen J, Cho E, Zhao J (2020) The effect of combined anterolateral and $\mathrm{ACL}$ reconstruction on reducing pivot shift rate and clinical outcomes: a meta-analysis. Arthroscopy 37(2):694-705

63. Zaffagnini S, Marcacci M, lo Presti M, Giordano G, lacono F, Neri MP, (2006) Prospective and randomized evaluation of $\mathrm{ACL}$ reconstruction with three techniques: a clinical and radiographic evaluation at 5 years follow-up. Knee Surg Sports Traumatol Arthrosc 14(11):1060-1069

64. Zaffagnini S, Marcheggiani Muccioli GM, Grassi A, Roberti di Sarsina T, Raggi F, Signorelli C, Urrizola F, Spinnato P, Rimondi E, Marcacci M (2017) Over-the-top ACL reconstruction plus extra-articular lateral tenodesis with hamstring tendon grafts: prospective evaluation with 20-year minimum follow-up. Am J Sports Med 45(14):3233-3242

65. Zeng X, Zhang Y, Kwong JSW, Zhang C, Li S, Sun F, Niu Y, Du L (2015) The methodological quality assessment tools for preclinical and clinical studies, systematic review and meta-analysis, and clinical practice guideline: a systematic review. J Evid Based Med 8(1):2-10

\section{Publisher's Note}

Springer Nature remains neutral with regard to jurisdictional claims in published maps and institutional affiliations.

\section{Submit your manuscript to a SpringerOpen ${ }^{\circ}$ journal and benefit from:}

- Convenient online submission

- Rigorous peer review

- Open access: articles freely available online

- High visibility within the field

- Retaining the copyright to your article

Submit your next manuscript at $\gg$ springeropen.com 